\title{
MORE SUSTAINABLE CONSTRUCTIONS USING LIMESTONE CALCINED CLAY CEMENT (LC $\left.{ }^{3}\right)$
}

\author{
Karen Scrivener, François Avet, Franco Zunino, Julien Ston \\ Laboratory of Construction Materials, EPFL, Lausanne, Switzerland
}

\begin{abstract}
Limestone Calcined Clay Cements $\left(\mathrm{LC}^{3}\right)$ permit to continue decreasing the clinker factor in cement. Two widely-available Supplementary Cementitious Materials (SCMs) are used in $\mathrm{LC}^{3}$ : calcined kaolinitic clays and limestone. The combination of these two SCMs allows additional reactions compared with conventional cements, leading to a high space-filling and excellent properties. Clays with only $40 \%$ of kaolinite can be used in $\mathrm{LC}^{3}$, providing sufficient strength, higher resistance to chloride ingress and alkali-silica reaction.
\end{abstract}

Keywords: Supplementary cementitious materials, limestone calcined clay cement, conventional cement, chloride ingress, alkali-silica reaction

\section{INTRODUCTION}

Cementitious materials account for more than half the "stuff" humanity produces. In the light of this, the fact that they account for only about $8 \%$ of man-made $\mathrm{CO} 2$ emissions reveals that they are environmentally friendly materials. But the industry has to do better, as the demand for cement is increasing to house the growing world population. As explained in detail elsewhere [1], cements and concrete incorporating supplementary cementitious materials (SCMs) are by far the most realistic means of significantly reducing the $\mathrm{CO}_{2}$ emissions associated with cementitious materials. Unfortunately, the availability of "classic" SCMs, fly ash and slag is very modest compared to the demand for cement [2]: around 15\% today and set to decrease in the future as we move away from burning coal and recycle more steel. Kaolinitic clays, calcined at $700-850^{\circ} \mathrm{C}$ are an important source of additional SCMs. Of particular interest is the substitution of clinker by a combination of calcined clay and limestone, which allows materials with similar mechanical properties to CEM I to be produced with as little as 50\% clinker [3]. This type of cement we have christened "LC3" - limestone calcined clay cement.

The secret behind the performance of this material is the very high pozzolanic reactivity of clay after calcination [4] and the synergetic reaction between alumina in the clay and limestone (calcium carbonate) [3, 5]. This leads to the formation of carboaluminate phases, which contribute to space filling and strength development.

The temperature for clay calcination is much lower than that for clinker production and there is no production of $\mathrm{CO} 2$ from the breakdown of the raw materials (this accounts to more than $60 \%$ of $\mathrm{CO} 2$ emissions related to clinker production). This means that the $\mathrm{CO} 2$ emissions of calcined clay are about $250 \mathrm{~kg} /$ tonne in contrast to around $850 \mathrm{~kg} /$ tonne for clinker production. In addition, the emissions associated with ground limestone are very low. This means that the $\mathrm{CO} 2$ associated with LC3 production is at least 30\% less than CEM I and even 10-20\% less than many CEM IIs or pozzolanic cements $[6,7]$. 


\section{Criteria for Suitable Clay}

Most people will be acquainted with metakaolin and know this is a very expensive product (about 3 times price of cement). The high cost of metakaolin is due to the high demands on purity and colour required by its main markets (paper, ceramics, refractories). $\mathrm{LC}^{3}$ technology does not require such expensive products, however; clays with a kaolinite content of as little as $40 \%$ perform very well, if not better than metakaolin [8]. Such clays are widely available around the world, especially in developing countries which is exactly where the demand for cement is growing. They are also frequently available as wastes - over or underburden from quarries where other materials are extracted, such as high grade china clay, or even from coal mining.

Figure 1 shows the strength results from more than 50 clays we have now tested from all over the world. The clays had very varied mineralogies, finenesses, calcination method, etc, but the strength (as tested in EN196 mortar bars) shows a good correlation with just one parameter the kaolin content. The red lines indicate the reference strengths of the same clinker as a CEM I. LC $^{3}$ produced from clays with more than about $40 \%$ kaolinite have strength similar to the CEM I reference from about 7 days [5]. It is very easy to access the amount of kaolinite in samples. The simplest is to heat the materials first to $400^{\circ} \mathrm{C}$, weight it and then heat to $650^{\circ} \mathrm{C}$. If the weight loss between the two heating steps is more than $6 \%$ then the material is likely suitable for $\mathrm{LC}^{3}$. More sophisticated analysis is possible by thermogravimetric analysis and $\mathrm{X}$ ray diffraction [9].

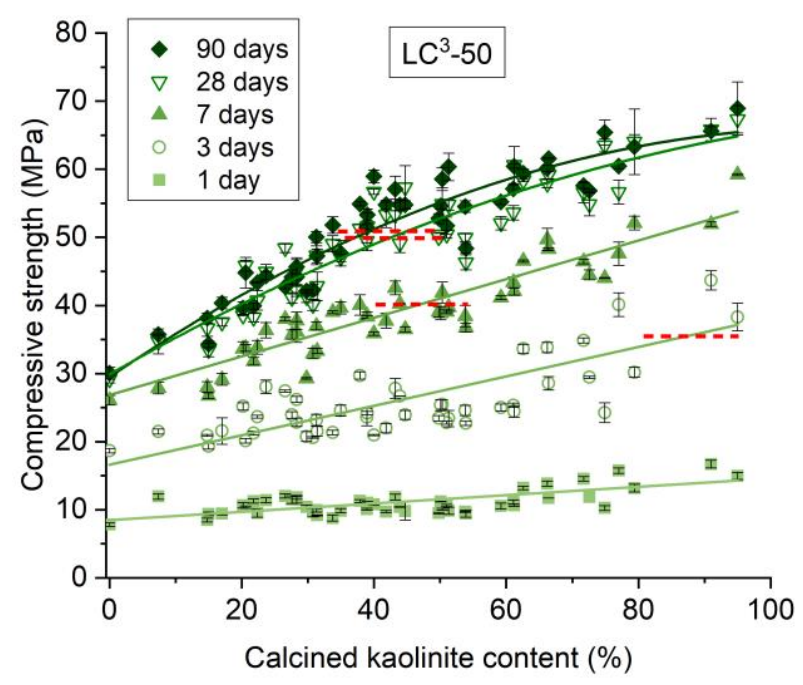

Figure 1. Compressive strength evolution of standard mortar over time versus the calcined kaolinite content of a variety of clays. The horizontal dashed lines represent the strength of $\mathrm{PC}$ at 3, 7, 28 and 90 days. From [5].

\section{Production}

Calcined clays can be produced very easily with existing cement making technologies. The production process seems to be very robust: trial materials have been produced at several sites in around the world in partnership with the LC3 project, notably in India [10][11], Cuba [12] and other countries in Latin America. We expect to see the first commercial productions starting in 2019. A detailed techno-economic feasibility study was made by Cementis [13] which 
showed that the production costs of LC3 are from 10-25\% cheaper for clay calcination at an integrated plant and 20-30\% cheaper for clay calcination at a grinding station. This means that very interesting payback times and returns on investment are possible.

These trial productions have been used to produce a range of demonstration structures, including the famous LC3 house near Jhansi in India, an annex to the Swiss embassy building in New Delhi, stretches of roadway and precast panels.

\section{Concerns: Workability, and Colour}

There are two main concerns people have regarding calcined clays: workability and colour. The workability is often questioned by people who have experience of using metakaolin, which (especially when produced by flash calcination) usually has an exceptionally high surface area and water demand. Two important differences of the $\mathrm{LC}^{3}$ technology substantially improve the workability compared to pure metakaolin, however. First the combined addition of limestone is important, as fine limestone is known to have a favourable impact of workability. Secondly, the use of clays with only $40 \%$ of metakaolin significantly improves the water demand since the impurities in the clay usually have lower surface area. Workability can be further improved by optimizing the particle size distribution and use of grinding aids. In practice, we have found that in concretes the amount of superplasticizer may need to be increased in some cases (in range 20-50\%) compared with plain cement, depending on concrete strength and desired workability. However, against this, the fluidity and cohesiveness of LC $^{3}$ concrete are exceptionally good, with no bleeding or segregation. This means that in applications such as self-compacting concrete the overall admixture cost may even be less as there is no need for additions such as viscosifiers to avoid segregation.

On the question of colour, this is related to the kind of impurities present in the clay. The presence of high amounts of iron oxide gives a reddish appearance to the clay. The colour will remain if the clay is calcined in an oxidising environment, but calcination in a reducing environment will lead to a grey colour similar to Portland cement clinker. Many manufacturers now sell calcination equipment in which it is possible to control the colour of the calcined clays as desired. Moreover, clays can also be found without iron impurities depending on the geology of the place.

\section{Durability Advantages}

On the plus side $\mathrm{LC}^{3}$ concrete has some major advantages compared to plain Portland cement and even other blended cements. Perhaps the most interesting is chloride resistance. Fig3 shows the chloride penetration after 6 months ponding in $3 \mathrm{wt} \%$. NaCl solution for Portland cement and a range of binary and ternary cement based on calcined clay, limestone and slag and fly ash [14]. The $\mathrm{LC}^{3}$ system shows by far the lowest penetration, despite having only $50 \%$ clinker content. Again, clays with only $40 \%$ of kaolinite outperforms the other systems [15]. The corrosion of rebars also occurs later than for plain cement, despite a slightly lower chloride threshold for $\mathrm{LC}^{3}$ [16]. Another durability advantage, is the ability to suppress expansive alkali silica reaction with reactive aggregates. We now have materials under test in alkaline solutions at $38^{\circ} \mathrm{C}$ for over 4 years with no sign of expansion, even with known highly reactive aggregates, whereas plain cement is highly-expansing [17]. 


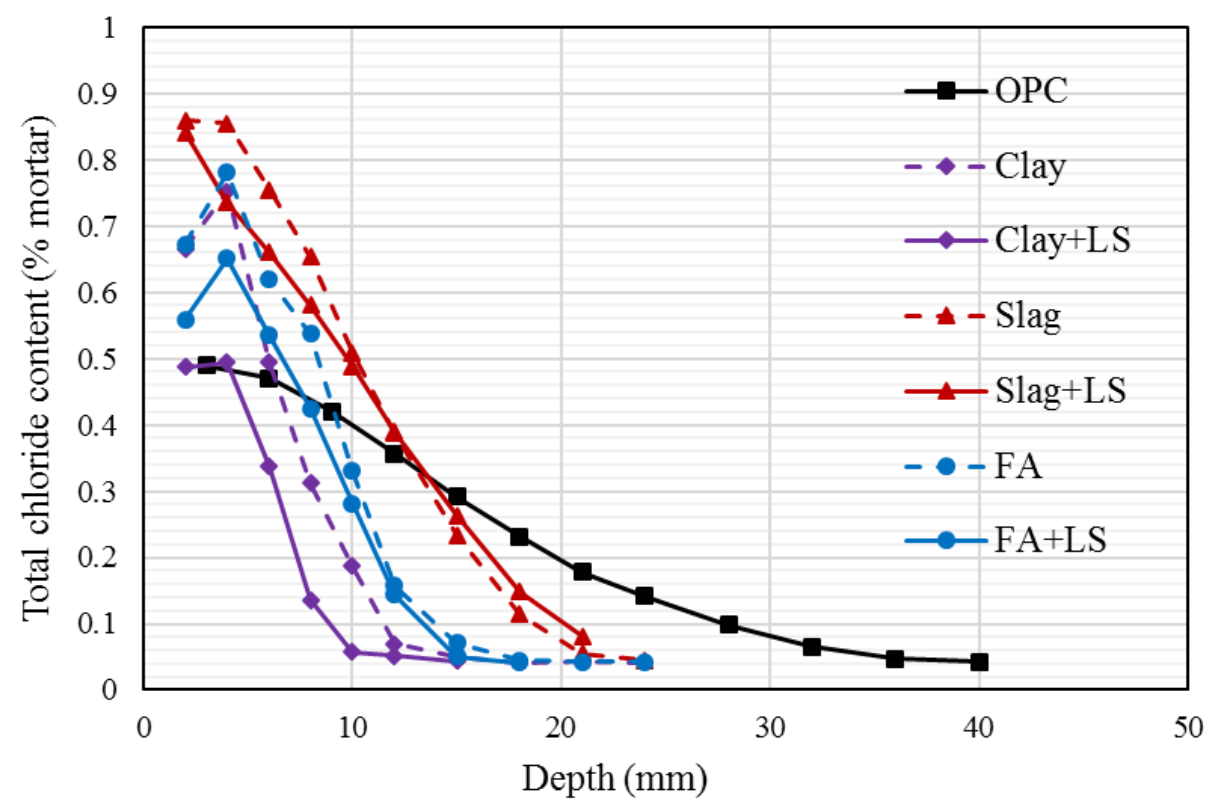

Figure 3. Chloride penetration after 6 months ponding of several systems containing slag, fly ash, limestone and $\mathrm{LC}^{3}$-based binders.

\section{CONCLUSION}

In conclusion, there is now increasing pressure on all industrial sectors to reduce their carbon footprint, to slow down global warming. For the cement industry $\mathrm{LC}^{3}$ technology has been demonstrated to be a robust and economic solution to lowering the clinker content and addressing the carbon issue. It is particularly adapted to regions with increasing need for construction materials, as the raw constituents are available worldwide and not dependent on other industries. The mechanical properties of $\mathrm{LC}^{3}$ blends containing as little as $50 \%$ clinker are comparable to plain Portland cement (CEM I). LC ${ }^{3}$ concrete shows exceptional durability with respect to chloride ion penetration and alkali silica reaction. The cost of implementing this technology in existing plants is moderate, as it requires similar equipment as for clinker production

\section{ACKNOWLEDGMENTS}

Financial support from Swiss Agency for Development and Cooperation (SDC) grant number 81026665 is acknowledged by the authors.

\section{REFERENCES}

1. Scrivener KL, John VM, Gartner EM (2016) Eco-efficient cements: Potential economically viable solutions for a low-CO2 cement-based materials industry

2. Snellings R (2016) Assessing, Understanding and Unlocking Supplementary Cementitious Materials. RILEM Tech Lett 1:50 . doi: 10.21809/rilemtechlett.2016.12

3. Antoni M, Rossen J, Martirena F, Scrivener K (2012) Cement substitution by a combination of metakaolin and limestone. Cem Concr Res 42:1579-1589 
4. Fernandez R, Martirena F, Scrivener KL (2011) The origin of the pozzolanic activity of calcined clay minerals: A comparison between kaolinite, illite and montmorillonite. Cem Concr Res 41:113-122 . doi: 10.1016/j.cemconres.2010.09.013

5. Avet F, Scrivener K (2018) Investigation of the calcined kaolinite content on the hydration of Limestone Calcined Clay Cement (LC3). Cem Concr Res 107:124-135 . doi: https://doi.org/10.1016/j.cemconres.2018.02.016

6. Sánchez Berriel S, Favier A, Rosa Domínguez E, et al (2016) Assessing the environmental and economic potential of Limestone Calcined Clay Cement in Cuba. J Clean Prod 124:361-369 . doi: 10.1016/j.jclepro.2016.02.125

7. Gettu R, Patel A, Rathi V, et al (2019) Influence of supplementary cementitious materials on the sustainability parameters of cements and concretes in the Indian context. Mater Struct 52:10 . doi: 10.1617/s11527-019-1321-5

8. Avet F, Snellings R, Alujas Diaz A, et al (2016) Development of a new rapid, relevant and reliable (R3) test method to evaluate the pozzolanic reactivity of calcined kaolinitic clays. Cem Concr Res 85:1-11 . doi: 10.1016/j.cemconres.2016.02.015

9. Avet F, Snellings R, Alujas Diaz A, et al (2016) Development of a new rapid, relevant and reliable $\left(\mathrm{R}^{3}\right)$ test method to evaluate the pozzolanic reactivity of calcined kaolinitic clays. Cem Concr Res 85: . doi: 10.1016/j.cemconres.2016.02.015

10. Bishnoi S, Maity S, Mallik A, et al (2014) Pilot scale manufacture of limestone calcined clay cement : The Indian experience. Indian Concr J 88:22-28

11. Emmanuel AC, Haldar P, Maity S, Bishnoi S (2016) Second pilot production of limestone calcined clay in India : The experience. Indian Concr J 90:57-64

12. Vizcaíno-Andrés LM, Sánchez-Berriel S, Damas-Carrera S, et al (2015) Industrial trial to produce a low clinker, low carbon cement. Mater Construcción 65:e045 . doi: $10.3989 / \mathrm{mc} .2015 .00614$

13. Cementis (2019) Report on LC3 Economical Feasibility

14. Sui S, Georget F, Maraghechi H, Scrivener K Developing a Generic Approach to Durability: Factors Affecting Chloride Transport in Binary and Ternary Cementitious Materials. Submitt to Cem Concr Res

15. Maraghechi H, Avet F, Wong H, et al (2018) Performance of Limestone Calcined Clay Cement (LC3) with various kaolinite contents with respect to chloride transport. Mater Struct 51:125 . doi: 10.1617/s11527-018-1255-3

16. Pillai RG, Gettu R, Santhanam M, et al (2019) Service life and life cycle assessment of reinforced concrete systems with limestone calcined clay cement (LC3). Cem Concr Res 118:111-119 . doi: https://doi.org/10.1016/j.cemconres.2018.11.019

17. Scrivener K, Avet F, Maraghechi H, et al (2018) Impacting factors and properties of Limestone Calcined Clay Cements (LC3). Green Mater 0:1-49 . doi: 10.1680/jgrma.18.00029 